their accounts by findings based on the monitoring of the centres using micro-based computer facilities.

During both days workshops were organised around five themes: planning and targeting, management, teamwork, monitoring and working with the community. These provided an opportunity to explore areas not covered in the plenary sessions and to discuss important issues in more depth. Despite the fine weather and their timing after lunch these were enthusiastically attended and the issues hotly pursued. For planning, issues high on the agenda were the need to involve all interest groups in the planning procedure, to ensure that service objectives were achieved and that services were accessible to all groups living in the area.

The management workshops were particularly concerned with ways of resolving the ambiguities caused by separate line management structures and by role blurring within teams. In addition the need for both users and service workers to affect management decisions was seen as an important issue. The team provided the focus for two workshops which tackled the roles and perspectives of team members and the stereotypes of different disciplines. The participants' computer skills were put to the test in the monitoring workshops when examples of software packages for data collection were demonstrated. The issue of involving the local community and users in the planning and running of services, often seen as a difficulty for professionals, was tackled in the workshops on working with the community. The convenors, with experience in consumer involvement, outlined already existing schemes and implications for staff and consumers.

By the end of the conference a number of themes had emerged, which Tom Craig attempted to summarise. Two opposing views of CMHCs could be discerned: one an outgrowth of traditional services into the community, with accessibility for the base population; and the other as a new kind of service emphasising user and community control with weakened links with the remainder of the psychiatric services. Given current service and political constraints a compromise between these views seemed to be more credible, with perhaps the CMHCs providing a focus for links with the community and between primary care, psychiatric, social and voluntary services. Locally based teams are in a position to initiate innovative schemes of prevention and education which need not endanger the funding of care for the chronic and severely mentally ill. They can also involve community members and users of services in decision making in a way that was not possible in traditional hospital based settings.

There is, however, a possible penalty to be paid for such a rapid growth of diverse centres. A lack of co-ordination creates a danger of loss of overall perspective and blurring of aims as occurred in the USA. These risks are minimised when services have precise goals and are effectively monitored. The introduction of low cost micro-computer systems and thoughtful methods of evaluation can cut out the time lag common in research and provide rapid feedback to teams and planners, enabling them to maintain a clear direction.

The conference provided more questions than answers, a situation fitting for such a rapidly changing area as the development of psychiatric services in the UK. The delegates left requesting more conferences and workshops on the areas covered, requests that can hopefully be met in the future.

\title{
International Physicians for the Prevention of Nuclear War VIIth World Congress, Moscow, May/June 1987 \\ "A New Manner of Thinking"
}

\author{
Tharu NaIDOo, Consultant Child and Adolescent Psychiatrist, Tetherdown Child Guidance Clinic,
} London N10

The Congress provided four packed and absorbing days. Most delegates stayed at the Rossiya Hotel, which has 6000 rooms and 28 restaurants where we were well fed. An efficient bus service ran between hotel and the modern Soviet Centre complex, complete with shopping arcades, fountains and glass-fronted lifts, where the Congress was held. After initial hiccups, the Congress was well organised and an excellent social programme laid on which included the Bolshoi, Moscow Circus and a televised concert.
International Physicians for the Prevention of Nuclear War (IPPNW) founded in 1980 by two cardiologists - an American, Dr Lown, and a Soviet, Dr Chazov - has grown rapidly; nearly 3000 delegates from 55 countries attended this Congress compared with about 50 at its first. IPPNW's principles derive from a knowledge of the consequences of thermo-nuclear explosions which it has done much to publicise. Since there is no cure for nuclear war, which unlike conventional war would destroy civilisation and 
possibly life itself, it is IPPNW's aim to prevent it. IPPNW argues urgently for the abolition of nuclear weapons; 50,000 warheads are on constant alert restrained only by men and machines which, as Challenger and Chernobyl showed, can fail. There are hundreds of false nuclear alarms each year. A recurrent phrase of the Congress was that nuclear war is an accident waiting to happen. As if to demonstrate the fallibility of sophisticated defensive systems, Mr Rust of West Germany landed his plane beside the Kremlin on the eve of the Congress, just as tons of cannabis evade US defences every year.

The Congress began with a formal opening; there were plenary sessions beginning and ending with workshops and with presentations between, up to 11 running concurrently. Choice was difficult and only a flavour of the Congress can be given here. The speakers were international and included doctors, politicians, journalists, psychologists, scientists, a SALT negotiator, poets and a Hiroshima survivor who gave a moving eyewitness account of the aftermath of the bomb.

There were many themes, one of them the drain of the arms race on world resources. The US spends 450 billion dollars per year, or one million a minute, on the arms race and in total has spent 10 trillion dollars to confront the USSR. As Carl Sagan put it, enough to buy absolutely everything in the USA except the land.

The relationship of this to health was another theme in a world where 15 million children still die annually, a figure which could be halved by simple low-cost means, e.g. immunisation and oral rehydration. Only Scandinavia gives the $0.7 \%$ gross national product recommended by the United Nations to world development projects. In addition to the implications of physical health, papers were presented on the psychological effects of the nuclear age; many showed a high level of anxiety in the populations studied. One Finnish study found that young people compartmentalised their anxieties into a social and personal sphere and, while extremely anxious about the death of mankind through nuclear catastrophe, did not relate this to their own or their families' deaths. This split was fixed by about 18 years but was less evident in young children. Another study showed that children whose parents were engaged in anti-nuclear activity felt less helpless about their own capacity to do something.

Another theme was the specific role of doctors in confronting the arms race and the medical consequences of nuclear war. Dr Lown spoke of a "medical tradition unafraid to confront ugly truths" and challenged the description of an instrument of genocide to victim and aggressor alike as a weapon as it can confer no military advantage. The deterrence argument for stockpiling was questioned; deterrence needs only one bomb. Gwyn Dyer, USA, argued that the pattern of world wars goes back 350 years with an average inter-war period of 50 years, not 20 as the deterrence camp argue. The difference about the last two wars was the technology employed. We were reminded that madmen can gain control of even sophisticated countries, e.g. Stalin and Hitler, who could now have their fingers on a nuclear button.

Confronting truths also included confronting the militarisation of nuclear language where "central exchange" meant blowing up billions of people immediately and killing billions more from after-effects. Many argued that arming the world to the teeth has, in fact, decreased world security and that by eliminating nuclear weapons tension would lessen, with the resulting need for fewer not more conventional weapons.

The title of the Congress 'A New Manner of Thinking' was taken from a quotation by Einstein: "We shall require a substantially new manner of thinking if mankind is to survive." As one speaker put it, the political thinking of Atilla the Hun can have no place in the nuclear age. He questioned the thinking of scientists who perversely use their creativity to invent even more terrible instruments of destruction and take upon themselves the right to do so. World security was repeatedly presented as global or non-existent.

New political initiatives were proposed and, at the personal level, cultural exchanges and an examination of the images and suspicions each side has of the other. The Russian post-holocaust film Letter from a Dead Man was shown and will be screened on British TV. Interestingly in this it is a Soviet error which leads to war, not an unprovoked attack from outside. Soviet TV screened The Day After during the Congress.

Although USA/USSR relations to some extent dominated the Congress, nuclear proliferation was discussed. A medical student from Zimbabwe, representing the front line states, spoke of South Africa's ability to produce the bomb and preparedness to use it as a last resort in defence of apartheid.

On an optimistic note, parallels were drawn between IPPNWs goals and the successful international programme for the eradication of smallpox. The Congress generated energy, and a sense of urgency about the absolute necessity of nuclear disarmament before catastrophe occurs, as likely by accident as design.

The hardest task, it seems to me, is to persuade the general public that the possession of nuclear stockpiles is no option. 